INTERNATIONAL DESIGN CONFERENCE - DESIGN 2018

https://doi.org/10.21278/idc.2018.0330

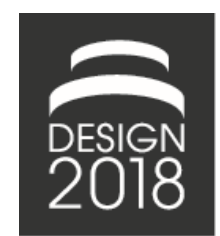

\title{
DEVELOPMENT OF A BIOINSPIRED APPROACH FOR THE DESIGN OF KINEMATIC CHAINS
}

\author{
M. Bartz, R. Gößling, R. Remus and B. Bender
}

\begin{abstract}
In recent years, bioinspired lightweight design has become a high priority in technology. An important source is the musculoskeletal system, which achieves a light construction by the interplay of different effects, which have the aim of minimizing bending stresses. In this paper the potentials for technology and the challenges for a transfer are discussed using kinematic chains as an example. An iterative approach is presented, which represents a solution to integrate the simultaneous optimization process of the musculoskeletal system into the technical product development process.
\end{abstract}

Keywords: lightweight design, biomimicry (biomimetics), biologically inspired design, inverse dynamics, topology optimisation

\section{Introduction}

In order to save energy and resources, there is a trend to lightweight constructions as an important strategy in the engineering design process. The aim of lightweight construction is to minimise mass by making full use of the structural robustness without weakening the stiffness or other constraints. Due to the low mass less resources are required, which can lead to functional and economic advantages. In mobile systems a lightweight design leads to low inertia, which can save kinetic energy and shortens movement time. This can for instance save time and money on production machines. On the other hand, the development of lightweight constructions entails higher costs, e.g. due to more complex development and manufacturing processes. For these reasons, a lightweight construction usually represents a local optimum under given boundary conditions. There is a conflict of aims between the lightest possible structure (functional benefit) and the required resources (cost). Determining an optimum between these aims is a central question in the development of technical products. Dedicated constructions, e.g. in the field of aerospace engineering, focus on functionality whereas development cost are not as important. In other areas, e.g. classical mechanical engineering (manufacturing), however, a compromise needs to be found between cost and functional benefits. Therefore, the determination of an optimum between resources used (costs) and functional advantages (benefits) is a central topic in the development of lightweight construction strategies (Weidemann, 2007; Klein, 2013). A way for the determination of an optimal lightweight structure under given boundary conditions (e.g. mass, energy, etc.) can be supported by the biological lightweight construction (Degischer et al., 2009; Nachtigall and Wisser, 2013). Biological constructions in nature are always subject to selection pressure within the framework of evolution, in which different organisms compete with each other. The design using a minimum of resources prevails under given boundary conditions. Therefore, biological lightweight constructions are an important source of ideas to solve technical lightweight problems because the organisms need metabolic energy for material synthesis and use it sparingly (VDI, 2012). The field of research dealing with the transfer of biological principles to technological applications is 
biomimetics. Within the framework of functional morphology, the relationship between form and function of elements of living beings is investigated (von Gleich et al., 2007).

This paper presents a bionic approach to support the design of technical systems conceived as kinematic chains. The aim is to exploit the lightweight construction potential of a previously unused interplay of lightweight construction effects of the musculoskeletal system of vertebrates.

\section{Bioinspired mechanisms in musculoskeletal systems and their potential for transfer into technical applications}

The musculoskeletal system of vertebrates is an important source of lightweight mechanisms, although some effects have already been converted into technical applications and others have not yet been implemented. The lightweight construction of the vertebrate musculoskeletal system is based on a combination of various lightweight design principles operating on different levels. The strength of the bone results from a hierarchical structure of the bone structure, by pairing of hard and tough components (Fratz-Zelman et al., 2011; Weiner et al., 2011). In addition to this material-related lightweight composite construction, the muscularskeleton system achieves a light construction due to the interplay of three effects. The combination of these effects aim at minimizing bending stress (or stress gradients and stress peaks) in order to create a homogeneous material stress, by which mass and resources can be saved. The effects are:

1. Functional adaptation and modification of bone mass along the major stress pathways

2. Active and passive tension chording through muscle forces and tendons

3. Bending minimized movement control of the extremities by the motor system

Functional adaptation allows the bone to adapt its shape and density to mechanical stress in order to minimize stress maxima (Wolf, 1892). This enables efficient use of materials and resources (Turner, 1998; Frost, 2003; Sugiyama et al., 2012). Tension chording by means of muscles and tendons enables the transformation of external bending loads by the introduction of force from muscle forces into a physiologically more favourable compression load. The compensation of bending loads is advantageous in the musculoskeletal system, as bone has a higher compressive strength than bending strength due to its microscopic structure. Muscle forces act multifunctionally because, in addition to the movement of the bones, they compensate bending loads by active force application. By actively compensating for bending loads, resources and weight can be saved in the bone while maintaining the same load-bearing capacity (Pauwels, 1965). Another lightweight effect is the active, bending minimized movement control of the outer extremities. The motoric system of the body strives to avoid unfavourable leverage and acceleration that can lead to bending loads (Pauwels, 1965).

From the three lightweight construction effects mentioned above, several approaches have already been transferred into technical applications. The principle of functional adaptations has already been implemented in many technical solutions for structural optimization. Design methods derived from the functional adaptation can be found in computer-assisted methods for the structural optimization and synthesis of technical components, such as e.g. in the soft-kill option (SKO), finite-element structure synthesis (FESS) and in evolutionary structure optimization methods based on the theory of porous media. (Matthek, 1997; Witzel and Preuschoft, 2005; Ricken et al., 2007; Gößling, 2010; Bartz et al., 2016; DIN ISO, 2016; VDI, 2017). The passive tension chording is taken into account in static constructions, e. g. cranes (Pauwels, 1965). The principle of active tension chording has not yet been implemented. Motion control is used in technology, but not in the kind of bending minimization that occurs in the musculoskeletal system.

An important point in the lightweight construction of the musculoskeletal system is that the optimal lightweight construction is not achieved by a single effect, but by a coordinated interaction of all effects. The lightweight construction mechanisms are in a state of balance (homeostasis). It is assumed that the biological system is thus in an optimal state of energy consumption and structural exploitation (Flechtner, 1972; Borck, 2014). Due to the complex control behaviour of the muscularskeletal system, also known as cybernetics, it is not possible to observe from outside the system how the system manages to regulate optimally. Thus the influences of the different effects and their interdependencies cannot be distinguished or understood in detail. 
The described interaction of forces and structures (or of form and function), as it occurs in the musculoskeletal system, is not used in technical systems yet. The optimisation of engineering designs takes place sequentially: At the beginning of the design, the forces necessary for the system function are determined. In the biological system, the functional adaptation of structure and forces takes place synchronously.

The described leads to the following questions. The first question is whether the interaction, as it is in the muscularskeletal system, can provide an advantage for technical systems in terms of mass minimization. Goessling et al. (2014) showed that the mass can be minimized by minimizing the external bending loads by means of a downstream topology optimization. In order to further examine the potential for technical applications, the question arises as to what areas of application could be possible for such a combination. Due to the kinematic similarity of the extremities of the muscularskeletal system, possible fields of application are open kinematic chains.

\section{Application of biological lightweight principles to kinematic chains}

For a transfer and an examination of the lightweight construction potential of the muscularskeletal system in its entirety through a biomimetic process, a complete understanding of the interactions is necessary (Nachtigall and Wisser, 2013). Due to the cybernetic behaviour, a complete understanding of the interaction of the lightweight effects cannot be given in detail. For this reason, the application of lightweight construction effects will be discussed individually on a simple bending beam in order to examine the advantages of an interplay of the effects and to discuss possible solutions for an optimal interaction.

On the basis of Figure 1, a simple bending beam (1.1) is used to explain how the structure can be optimized using biological optimization algorithms oriented to the musculoskeletal system. The bending beam, a cantilever arm of length 1 , is loaded by the force $F$. The bending moment curve increases linearly up to the clamping point to the maximum bending moment $M_{\max }$. In this example, the cross section is assumed to be a full circle profile with diameter $\mathrm{d}$. The modulus of resistance and the maximum stress as a function of the location on the longitudinal axis $\mathrm{x}$ are calculated with the formulas in the right part of the illustration. The occurring stresses depend on the cross-section. In the classical case (1.2), a minimum diameter $d_{\min }$ for the profile is determined for the location of the maximum bending moment, here the clamping. If the cross-section is taken as constant, the maximum stress along the beam axis also occurs in the clamping. All other areas have a lower stress, because the bending moments are lower and the cross-section is therefore oversized. Here, the potential for lightweight construction arises, in which the beam is adapted at each point along the longitudinal axis in such a way that the stresses occurring are just below the permissible stress $\sigma_{z u l}(1.3)$. This lightweight construction strategy is known as the "constant stress axiom" (according to Matthek, 1997; Klein, 2013; VDI, 2017) and is inspired by the growth behaviour of trees and bones, where the structures are designed for full loadbearing capacity. With this well-known bioinspired procedure, mass can be saved while maintaining the same load-bearing capacity. Table 1 compares the volumes, which also allow a comparison of the masses at constant density. As shown in the table, the variable cross section leads to $40 \%$ less volume and thus mass at constant density. However, the stress has only been homogenized along the longitudinal axis (x-axis), not across the cross-section, as a stress gradient remains due to bending. According to Pauwels (1965), in the bones of vertebrates, bending minimization is achieved due to the three mentioned lightweight construction effects of the musculoskeletal system. Due to the static example, a bending minimized motion control is not considered in this case.

The mechanisms that can minimize bending in the beam are functional adaptation (1.4) and tension chording (1.5). Due to the functional adaptation, implemented here by a topology optimization, the longitudinal axis of the beam can change so that mainly tensile and compressive forces occur. In addition, the tension chording works by compensating external bending moments by tension in the form of pull ropes (which, in addition to the tension chording, can also generate movement). The figure shows the synthesized structure as a result of topology optimization (1.4). The aim was to minimize bending stresses with maximum stiffness. Compression and tension arches are visible, which mainly transmit normal forces. This corresponds to a purely stress-controlled functional modification, such as the rebuilding process in the musculoskeletal system. The results of the volume of the two cases are also listed in Table 1. 


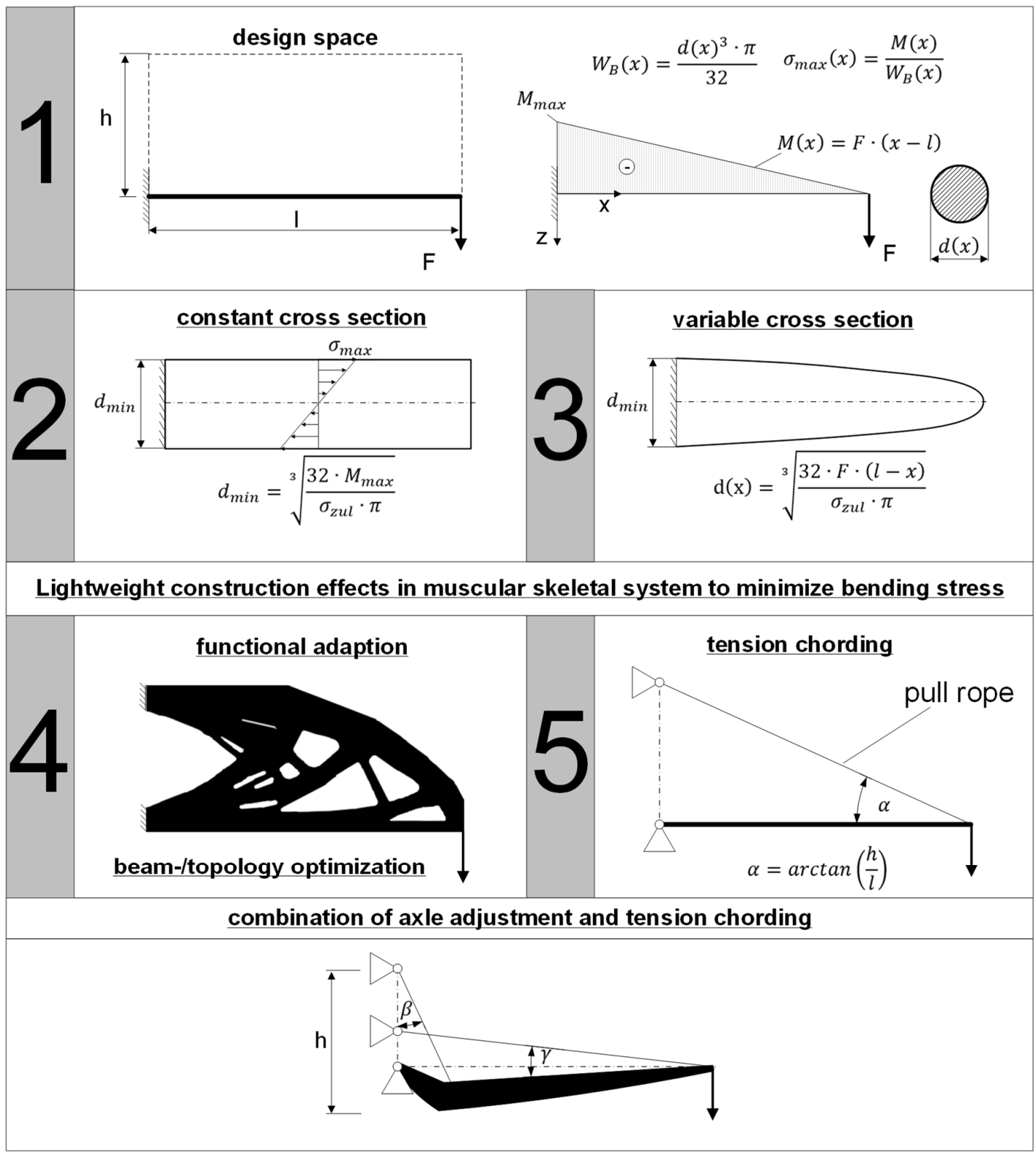

Figure 1. Interplay of lightweight construction effects

Table 1. Comparison of volumes $\left(l=0,4 \mathrm{~m} ; F=300 \mathrm{~N} ; \sigma_{\mathrm{zul}}=20 \mathrm{MPa} ; \mathrm{h}=\frac{l}{2}\right)$

\begin{tabular}{|l|c|c|c|}
\hline & Calculation: $V=\int_{0}^{l} \frac{d(x)^{2}}{4} \cdot \pi d x$ & Volume $\left[\mathrm{mm}^{3}\right]$ & ratio to $V_{2}$ \\
\hline constant cross section & $V_{2}=\frac{\mathrm{d}_{\mathrm{min}}^{2}}{4} \cdot \pi \cdot l$ & $487.425,8$ & $100 \%$ \\
\hline variable cross section & $V_{3}=\frac{\pi}{4} \cdot\left(\frac{32 \cdot F}{\sigma_{z u l} \cdot \pi}\right)^{\frac{2}{3}} \cdot\left[-\frac{3}{5} \cdot(l-x)^{\frac{5}{3}}\right]_{0}^{l}$ & $292.461,5$ & $60 \%$ \\
\hline Topology & $V_{4}=\int d V$ & $\approx 10.000$ & $\approx 2-3 \%$ \\
\hline tension chording & $V_{5}=\frac{F \cdot l}{\sigma_{z u l} \cdot \tan (\alpha)}$ & 12.000 & $2,5 \%$ \\
\hline combination & - & $\approx 10.000$ & $\approx 2 \%$ \\
\hline
\end{tabular}


As the table shows, the cases (1.4) and (1.5) have a markedly smaller volume than the cases (1.2) and (3). This is due to the fact that bending stresses were avoided by adjusting function and shape. (1.4) achieves a minimum mass by purely structural reconstruction. (1.5) shows the advantage that the bend minimising ropes can take on functional tasks, such as generating a movement. However, the two solutions also suffer disadvantages. The result of the topology optimization is difficult to produce as it is of complex structure. Tension chording in system (1.5) minimizes the bending moment at the expense of introducing a high normal force into the system. The lower the height $h$, the higher the required tractive force and the higher the normal stress and the risk of kinking. The musculoskeletal system addresses the problem by choosing the optimal from cases (1.4) and (1.5) depending on the boundary conditions. Boundary conditions are e. g. the required kinematics of the system, which muscular forces are available and which lever ratios emerge. The lower part of the illustration shows a possible (not necessarily optimal) solution, in which the beam axis was adapted and different tension chords forces are introduced into the system (according to Pauwels, 1965). A comparison with table 1 shows that this combination can reduce volume further.

The example discussed shows there is a great variety of shapes and forces to ensure a functioning of the system, but there are different locale optima. The question is, as with so many possibilities, how to find an optimal solution under given boundary conditions. Problems with many parameters to optimize a target function (here the minimum mass) can be solved with mathematical optimization methods. A large number of procedures have already been used in the area of lightweight construction for different applications (Harzheim, 2014; VDI, 2017). Here, too, some findings can be transferred from biology to technology. This will be discussed together with the following example of muscular play (Figure 2). An optimization method that is applied in the area of determining muscle forces is the inverted dynamic calculation. This procedure can be used to help determine the optimum. The procedure is explained in the following figure on the example of the flexion of the upper arm.

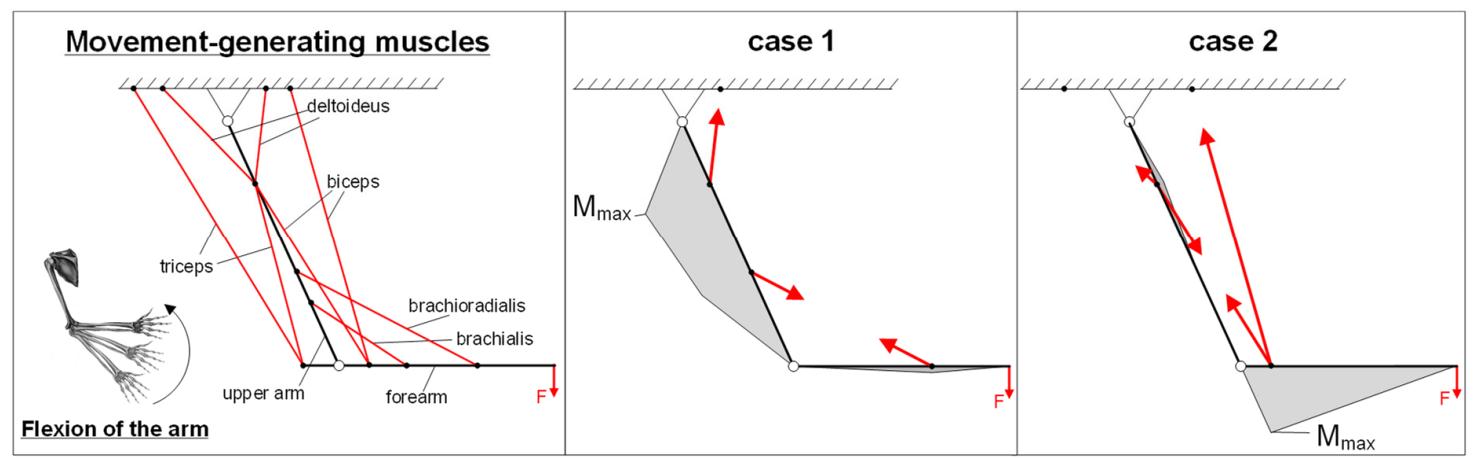

Figure 2. Redundant motion generation using the flexion of the arm

A flexion of the arm can be generated by a varying number of muscular forces, in this case eight muscles (Richard and Kullmer, 2013; Gößling et al., 2017). These forces can interact in different configurations to create the same motion. The right part of the figure shows two extreme cases. In the left part of the figure, the movement is generated by the forearm spoke muscle (brachioradialis) and the shoulder muscle (deltoideus). The bending load is minimal in the forearm and maximum in the upper arm. In the right part, the movement is mainly generated by the biceps, which causes a high bending load in the forearm. Both force combinations produce the same movement of the arm. However, each force combination produces different loads in the bone. The mathematical method of inverse dynamics can be used to find out the possible causes (forces) of such problems where the desired effect (movement and minimum bending load) is to be deduced.

Inverse dynamic methods are already used in multi-body simulation programs for musculoskeletal movements and also for the regulation of humanoid robots (Mombaur, 2001; Damsgaard et al., 2006; Schultz and Mombaur, 2010; Gößling et al., 2014; Lutz et al., 2016; Gößling et al., 2017). This procedure can also be used to determine the actuator force according to biological models for 
technical systems, e.g. in the tuning of the movement forces for a robot system. By combining the determination of the movement force (function) and an adapted structure by topology optimization (shape), a weight-minimum solution can be achieved.

\section{Development of an integrated approach to the design of kinematic chains}

There is a large number of variations on how the tension chording and functional adjustment can interact. In biology, the optimisation process takes place simultaneously. The new approach is intended to take account of this simultaneous process within the framework of the classical design by means of an iterative approach. The new approach is to be developed on the basis of systems that are kinematically similar to the extremities of the musculoskeletal system. This applies to open kinematic chains. In the following, the new approach will be explained using the example of a two-joint robot, as shown in Figure 4. The design process is shown in Figure 3.

The aim in the design of a lightweight structure is to achieve a minimum mass. The new approach differs from the classical design in that the determination of the forces required for functionality and the geometry are not determined sequentially but in an iterative process.

At the beginning of the design process, the requirements are defined in the form of boundary conditions. This includes external loads, kinematics, and required and available energy. Based on this information, pre-dimensioning is carried out at the start of concept development. The next step is to find concepts for the movement. Using the example of the double-joint arm robot, these are the forces and moments enabling the arms to move. The movement of the arm can take place by means of different mechanisms of action. Traditional industrial robot systems use articulated motors for this purpose, which transmit torques into the joints and thus enable the movement of the arms. In this example one motor per joint and degree of freedom. In the next step of the classical design, a multibody simulation is used to determine the temporal course of the loads necessary for defined paths. Based on these loads, all functions can be implemented in the geometry and a topology optimization can be carried out. Finally, a finite element analysis is conducted to determine whether a proof of strength is provided.

In contrast to the described classical procedure, the new approach starts with the determination of the forces for the movement. As in the example of the arm movement shown in Figure 2 is created by the interaction of several forces. First of all, a motor in the joint appears sufficient, but by means of a specific selection and arrangement of forces, an energy-saving movement can be generated and bending loads in the arms can be minimized by the principle of the tension chording. In the new approach, this is achieved by the fact that the number and position of forces in terms of the tension chord according to Pauwels (1965) are already introduced in the concepts. The arrangement and variation of the initiation points is varied only during concept development until a solution with minimal bending is found and is not changed in the further iterative procedure. The following procedure implements the unknown interaction between functional adaptation and tension chording. First, as in the classic case, the necessary movement forces are determined by a multi-body simulation. In contrast to the classical design, a further boundary condition is implemented in the inverse dynamic optimization process, namely that the accelerations are selected in such a way that the bending moments resulting from the inertia are kept to a minimum. As in the classic case, the loads are used to create a geometry that implements the required functions and topology optimization is carried out. In order to take into account the interaction between form and function as in the biological model, the new structure, which possesses a different mass and inertia, is returned to the determination of new movement forces. Now a new calculation of the movement forces takes place, as the bending moment load may have changed due to the changed mass. This loop is executed until the mass does not change further. When the mass does not change anymore, a finite element analysis is used to check whether the load-bearing capacity of the structure is sufficient. 


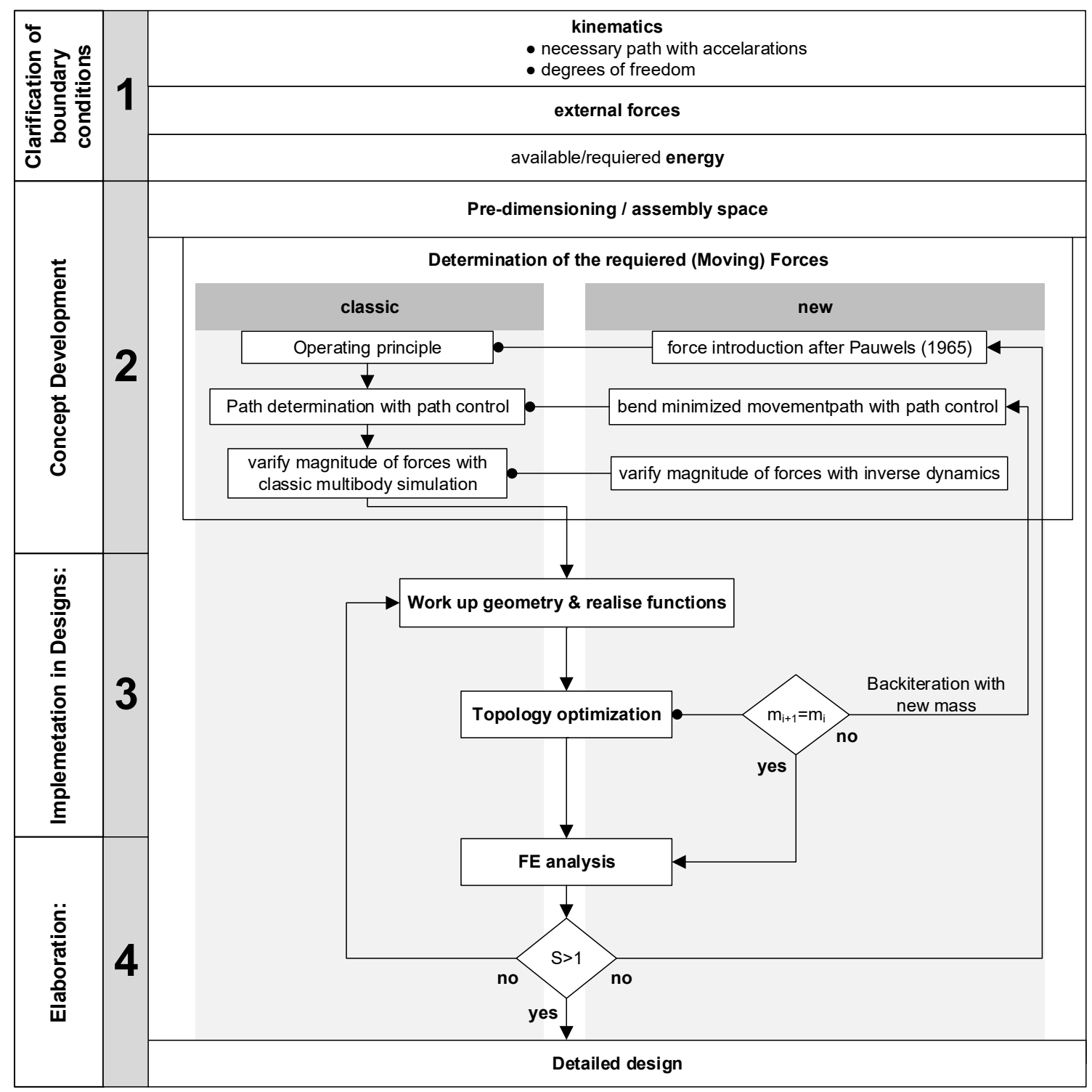

Figure 3. Procedure of the new approach, classical design of lightweight structures based on Klein (2017)

\section{Application of the new approach to a double-joint arm robot}

The procedure shown in Figure 3 is a first attempt to extend the classic approach. Of course, the exchange of the operating principles of the drive (expandable tensile elements instead of electric motors) also results in disadvantages with regard to dynamics and response behaviour as well as universal applicability. However, the fundamental potential for application in lightweight construction will be investigated by means of a concrete example below to show its potential. For this purpose, a doublejoint arm robot was used as shown in Figure 4. The difference in the conceptual design is that the drive is not provided by electric motors in the joints, but by a belt drive allowing a minimum bending force to be applied. The models shown are the first concepts of design space before the optimization loop was to be carried out for weight reduction. 

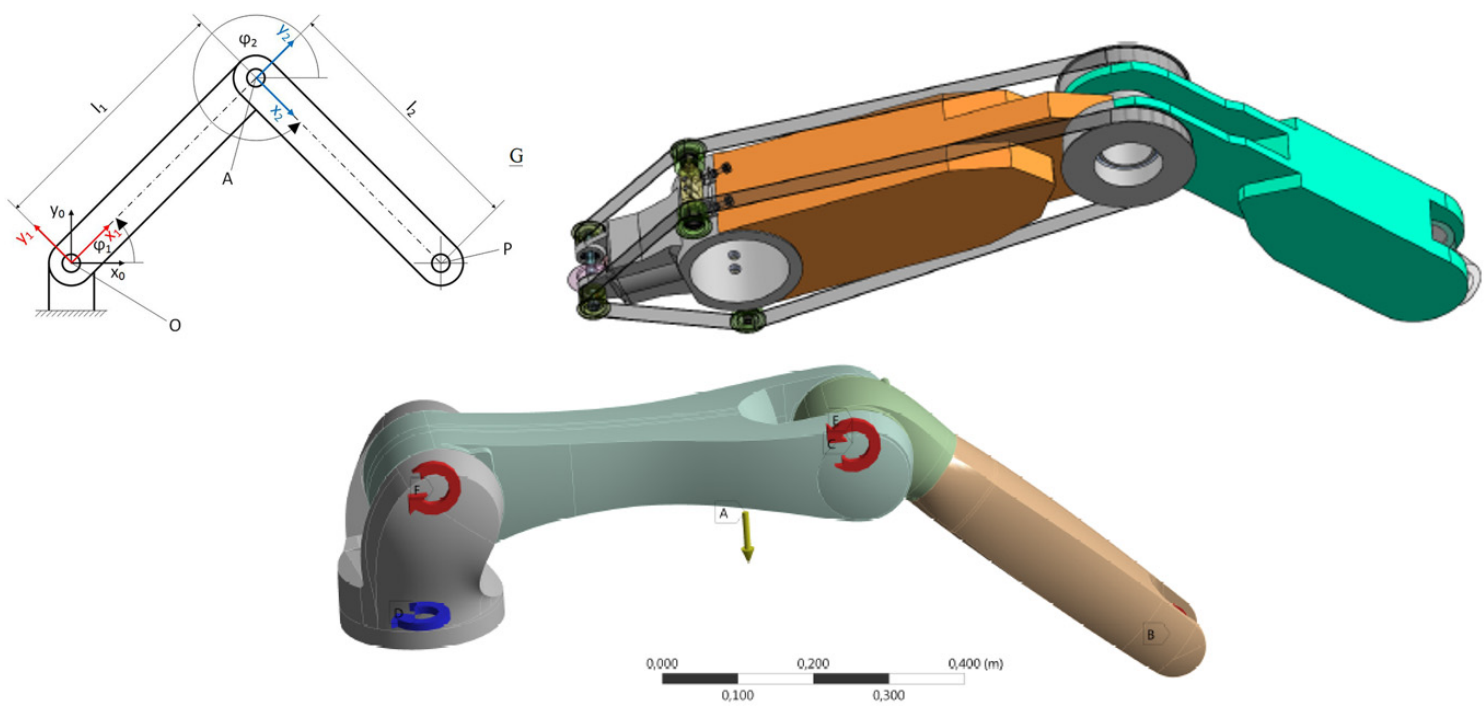

Figure 4. Conception of the double-joint arm robot

The robot arm is designed for a defined path curve. Both systems, both classical and bioinspired, go through the procedure described in Section 4. The following figure shows the von-Mises-stress in the first arm over time and over the longitudinal axis. A direct comparison shows that both the absolute and average stress values are lower in the bioinspired case than in the classical case. The spatial homogenization of the tension is due to the arrangement and interaction of the forces of movement. The temporal homogenization follows the bending minimized path control. The temporal and spatial homogeneity of the stresses corresponds to the expectations according to the mechanisms of action in the musculoskeletal system.
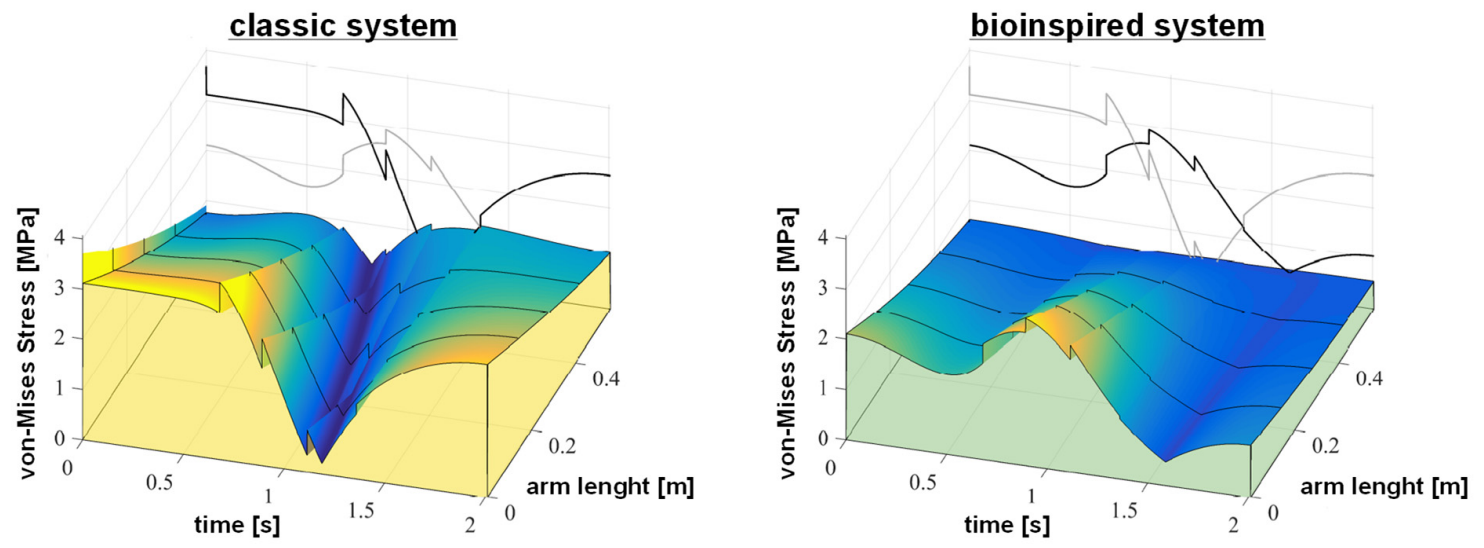

Figure 5. Comparison of the von-Mises-stress in the lower arm

With the help of the loads occurring during movement, a first constructional space model is created. Due to the additional straps that implement the tension chording, the mass of the bioinspired initial concept before topology optimization is even larger than that of the classic variants due to the higher installation space. The models continue to run through the procedure shown in Figure 3. The iterative approach by coupling topology optimization and bending minimized motion control leads to a convergence and thus to a finished structure after several integration steps. The synthesized structures after convergence are compared as a result in Figure 6. Despite a higher initial mass, the bioinspired variant ends up below the classical variant after the using new procedure. The first arm is more than $20 \%$ lighter, the second arm more than $30 \%$ lighter than in the classic version. 


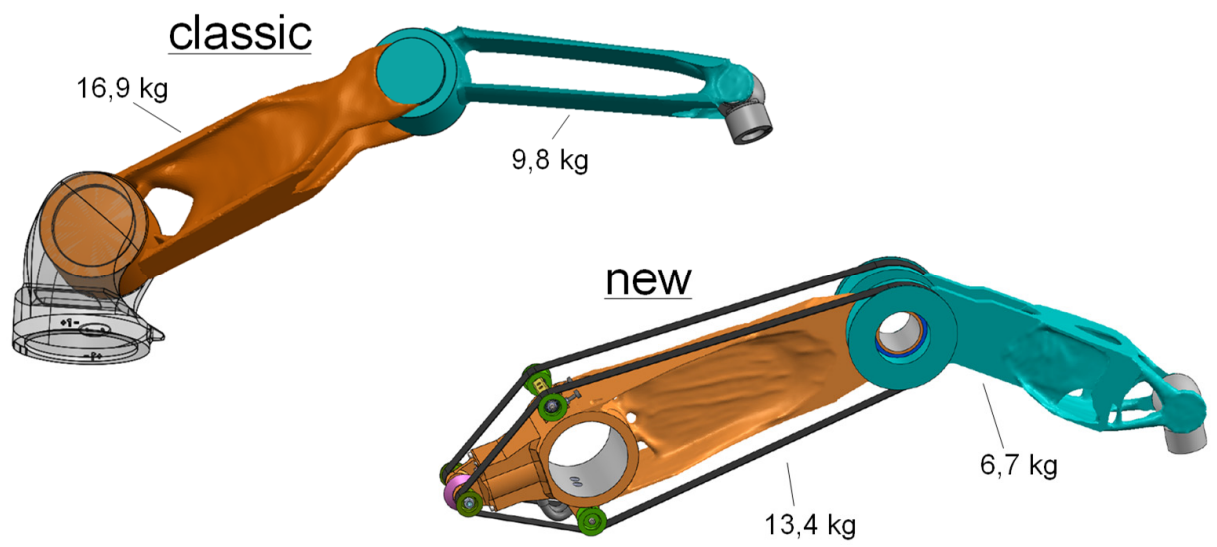

Figure 6. Comparison of the classical and bioinspired variants

\section{Summary and future work}

Based on a biomimetic process, this paper presented the interaction of the lightweight construction effects of the musculoskeletal system as potential for mass minimization of technical systems. By means of a simple bending beam, it could be shown that a combination of topology optimization and tension chording can lead to a system with a low mass. With the help of inverse dynamics, that is already used to determine muscle forces, an optimal combination of the effects can be determined by coupling the topology optimization and tension chording in an iterative procedure. Due to the kinematic similarity of the musculoskeletal system to open kinematic chains, the described interaction of these systems was investigated. For these systems, a new approach has been developed to illustrate how in the product development process of lightweight constructions, an interaction between topology optimization and tension chording can be implemented in an iterative process. By means of a double-joint arm robot, it could be demonstrated with this approach that the combination of topology optimization and tension belting leads to a mass minimization of $20-30 \%$, while maintaining the kinematic functionality.

However, this represents a first basic investigation for potential and possible technical applications. Replacement of the basic operating principle, articulated motors are replaced by tensioning belts, causes other possible disadvantages. The dynamics and control behaviour change fundamentally due to the higher flexibility of the control elements. Furthermore, in the example presented, the tension belting is designed for certain load cases only. In other load cases, the tensioning strap is not used and the structure is not sufficiently relieved of bending strain. It is therefore important to investigate further advantages and disadvantages of the new approach in follow-up work. One of the most important points here is to find further technical fields of application, which can be supported by the principle of technically meaningful support.

\section{References}

Bartz, M., Waschinski, N., Gößling, R., Bender, B. and Ricken, T. (2016), “Entwicklung eines mehrphasigen FEModells zur Analyse der mechanischen Spannungen im Oberschenkelknochen unter physiologischen Belastungen", Proceedings of the 34th CADFEM ANSYS Simulation Conference, Nürnberg, Germany, October 5-7, 2016, CADFEM ANSYS.

Borck, C. (2014), "Die Weisheit der Homöostase und die Freiheit des Körpers, Walter B. Cannons integrierte Theorie des Organismus", Zeithistorische Forschungen/Studies in Contemporary History, Vol. 11 No. 3, pp. 472-477.

Damsgaard, M., Rasmussen, J., Christensen, S.T., Surma, E. and de Zee, M. (2006), “Analysis of musculoskeletal systems in the AnyBody Modeling System”, Simulation Modelling Practice and Theory, Vol. 14 No. 8, pp. 1100-1111. https://doi.org/10.1016/j.simpat.2006.09.001

Degischer, P. and Lüftl, S. (2009), Leichtbau: Prinzipien, Werkstoffauswahl und Fertigungsvarianten, Wiley$\mathrm{VCH}$, Weinheim.

DIN ISO (2016), 18459:2016-08 Biomimetics - Biomimetic structural optimization (ISO 18459:2015), DIN.

Flechtner, H.J. (1972), Grundbegriffe der Kybernetik, Hirzel S. Verlag, Stuttgart. 
Fratz-Zelman, N., Misof, B.M. and Roschger, P. (2011), "Das Knochenmaterial: Ein Nano-Komposit aus Mineral und Kollagen”, Journal für Mineralstoffwechsel and Muskuloskelettale Erkrankungen, Vol. 18 No. 3, pp. 110117.

Frost, H. (2003), “Bone's mechanostat: a 2003 update”, The anatomical record. Part A, Discoveries in molecular, cellular, and evolutionary biology, Vol. 275A No. 2, pp. 1081-1101. https://doi.org/10.1002/ar.a.10119

Gößling, R. (2010), Biologische Vorteile und mechanische Probleme der langen Schnauze am Beispiel Plateosaurus, PhD thesis, Ruhr-Universität Bochum.

Gößling, R., Bartz, M., Uttich, E. and Bender, B. (2017), "Inversdynamische Berechnungen der Muskelkräfte am Glenohumeralgelenk unter der Prämisse der Biegeminimierung", Proceedings of the 35th CADFEM ANSYS Simulation Conference, Koblenz, Germany, November 15-17, 2017.

Gößling, R., Herzog, M., Witzel, U. and Bender, B. (2014), "Compensation of bending moments as a natureinspired design principle?", Proceedings of the DESIGN 2014 / 13th International Design Conference, Dubrovnik, Croatia, May 19-22, 2014, The Design Society, Glasgow, pp. 193-200.

Harzheim, L. (2014), Strukturoptimierung: Grundlagen und Anwendungen, 2nd ed., Europa-Lehrmittel Verlag, Haan-Gruiten.

Klein, B. (2013), Leichtbau-Konstruktion: Berechnungsgrundlagen und Gestaltung, 10th ed., Springer, Wiesbaden. https://doi.org/10.1007/978-3-658-02272-3

Lutz, F., Mastel, R., Runge, M., Stief, F., Schmidt, A. et al. (2016), “Calculation of muscle forces during normal gait under consideration of femoral bending moments”, Medical Engineering \& Physics, Vol. 38 No. 9, pp. 1008-1015. https://doi.org/10.1016/j.medengphy.2016.05.005

Matthek, C. (1997), Design in der Natur: Der Baum als Lehrmeister, 3rd ed., Rombach Verlang, Freiburg.

Mombaur, K. (2001), Stability optimization of open-loop controlled walking robots, $\mathrm{PhD}$ thesis, Universität Heidelberg.

Nachtigall, W. and Wisser, A. (2013), Bionik in Beispielen: 250 illustrierte Ansätze, Springer Spektrum, Berlin, Heidelberg. https://doi.org/10.1007/978-3-642-34767-2

Pauwels, F. (1965), Gesammelte Abhandlungen zur Funktionellen Anatomie des Bewegungsapparates, Springer Verlag, Berlin. https://doi.org/10.1007/978-3-642-86841-2

Richard, H.A. and Kullmer, G. (2013), Biomechanik: Grundlagen und Anwendungen auf den menschlichen Bewegungsapparat, Springer Vieweg, Wiesbaden. https://doi.org/10.1007/978-3-8348-8611-8

Ricken, T., Schwarz, A. and Bluhm, J. (2007), “A triphasic model of transversely isotropic biological tissue with applications to stress and biologically induced growth”, Computational Materials Science, Vol. 39 No. 1, pp. 124-136. https://doi.org/10.1016/j.commatsci.2006.03.025

Schultz, G. and Mombaur, K. (2010), "Modeling and Optimal Control of Human-Like Running", IEEE/ASME Transactions on Mechatronics, Vol. 15 No. 5, pp. 783-792. https://doi.org/10.1109/TMECH.2009.2035112

Sugiyama, T., Meakin, L.B., Browne, W.J., Galea, G.L., Price, J.S. and Lanyon, L.E. (2012), "Bones' adaptive response to mechanical loading is essentially linear between the low strains associated with disuse and the high strains associated with the lamellar/woven bone transition", Journal of Bone and Mineral Research, Vol. 27 No. 8, pp. 1784-1793. https://doi.org/10.1002/jbmr.1599

Turner, C.H. (1998), “Three rules for bone adaption to mechanical stimuli”, Bone, Vol. 23 No. 5, pp. 399-407. https://doi.org/10.1016/S8756-3282(98)00118-5

VDI (2012), VDI 6224 Blatt 1 Bionische Optimierung - Evolutionäre Algorithmen in der Anwendung, VDI.

VDI (2017), VDI 6224 Blatt 3 Bionik - Bionische Strukturoptimierung im Rahmen eines ganzheitlichen Produktentstehungsprozesses, VDI.

von Gleich, A., Pade, C., Petschow, U. and Pissarskoi, E. (2007), Bionik Aktuelle Trends und zukünftige Potenziale, ASCO Sturm Druck, Bremen.

Weidemann, J. (2007), Leichtbau - Elemente und Konstruktion, 3rd ed., Springer-Verlag, Berlin, Heidelberg. https://doi.org/10.1007/978-3-540-33657-0

Weiner, S. and Wagner, H.D. (1998), "The Material Bone: Structure-Mechanical Function Relations”, Annual Reviews Material Science, Vol. 28, pp. 271-298. https://doi.org/10.1146/annurev.matsci.28.1.271

Witzel, U. and Preuschoft, H. (2005), "Finite-element model construction for the virtual synthesis of the skulls in vertebrates: case study of Diplodocus", The Anatomical Record Part A: Discoveries in Molecular, Cellular, and Evolutionary Biology, 2005, Vol. 283A No. 2, pp. 391-401. https://doi.org/10.1002/ar.a.20174

Wolf, J. (1892), Das Gesetz der Transformation der Knochen, Hirschwald, Berlin.

Marcel Bartz, Diplom-Ingenieur

Ruhr-Universität Bochum, Lehrstuhl für Produktentwicklung

Universitätsstraße 150, 44801 Bochum, Germany

Email: bartz@lpe.rub.de 